\title{
The research-teaching nexus: Using a construction teaching event as a research tool
}

Maria del Mar Casanovas-Rubio ${ }^{\mathrm{a} *}$, Alison Ahearn ${ }^{\mathrm{b}}$, Gonzalo Ramos ${ }^{\mathrm{a}}$ and Sunday Popo$\mathrm{Ola}^{\mathrm{b}}$

${ }^{a}$ Department of Construction Engineering, Universitat Politècnica de Catalunya, Barcelona, Spain; ${ }^{b}$ Department of Civil and Environmental Engineering, Imperial College London, London, $U K$.

In principle, the research-teaching nexus should be seen as a two-way link, showing not only ways in which research supports teaching but also ways in which teaching supports research. In reality, the discussion has been limited almost entirely to the first of these practices. This paper presents a case study in which some student field-trip construction projects, originally designed as a teaching tool, were also used to undertake environmental research. The research consisted of testing the implementation of a tool for assessing the environmental impact of construction sites. It was conducted at the Imperial College London Constructionarium Field Module 2012 at the National Construction College, in England. The findings highlighted the unexploited research potential of the Constructionarium teaching tool specifically and of field-trip teaching events generally. To a lesser extent, the students also learned about the research content and process. This experience could be extended to other field-trip teaching events.

Keywords: research-teaching nexus; teaching-research nexus; teaching and research links; research/teaching; engineering education. 


\section{Introduction}

\section{Developing teaching to inform research}

The link between research and teaching is attracting significant international attention from both policy makers and academics (Healey, Jordan, Fell \& Short, 2010). There is a growing body of research on the topic (see for instance books by Barnett, 2005; Brew, 2001, 2006; Jenkins, Breen, Lindsay \& Brew, 2003; Kreber, 2006).

Recent work has begun to focus on what institutions, departments, disciplines and individuals may do to enhance the linkages for the benefit of student learning (Healey, 2005a, 2005b; Jenkins \& Healey, 2005; Jenkins et al., 2003; Jenkins, Healey \& Zetter, 2007). Elsen, Visser-Wijnveen, van der Rijst and van Driel (2009) explored how to strengthen the research-teaching nexus in university education, by relating policy and practice. Their findings show that, 'in general, academics view the connection between research and teaching positively, although, in practice, the potential benefits are not always realised'.

Building on the work of Griffiths (2004), Healey (2005b) explored the various ways in which the research-teaching nexus is understood. Later, it was adapted by Elsen et al. (2009). Thus, it is generally accepted that students may experience research in four main ways (Healey et al., 2010):

- Research-led: students learn about research findings, the curriculum content is dominated by faculty research interests and information transmission is the main teaching mode.

- Research-oriented: students learn about research processes, the curriculum emphasises the processes by which knowledge is produced on par with the research findings. 
- Research-based: students learn as researchers, through inquiry-based activities, minimising the division between teacher and student.

- Research-tutored: students learn in small group discussions with a tutor about research findings.

These classifications show how research can support teaching but does not include the ways in which how teaching can support research. Indeed, several authors (Griffiths, 2004; Prince, Felder \& Brent, 2007; Elsen et al., 2009) state that, conventionally, the flow is held to work mainly, if not solely, from the research to teaching.

It is not that teaching does not support research; it can do so in the following ways (Griffiths, 2004; Prince et al., 2007; Elsen et al., 2009):

- Teachers can gain deeper understanding of a subject by teaching it, facilitating research advances in that subject.

- Teaching encourages a wider intellectual context for researchers who are highly specialised.

- Students can provide feedback on research analysis, helping to identify flaws.

- A 'research-based' student learning activity can produce new research materials.

- Student projects can help to test the analytical frameworks that academic staff are developing, or provide the beginnings of comparative studies.

- $\quad$ New students are a stimulating form of pressure that can provide reassurance and motivation.

The advantages of strengthening the connection between research and teaching seem clear, and several studies encourage a stronger connection at both the researcher level and the institutional level (Prince et al., 2007). Built environmental disciplines (a range of practice-oriented subjects concerned with the design, development and management of buildings, spaces and places) have a number of characteristics that make 
them particularly fruitful for exploring the research-teaching nexus (Griffiths, 2004). Nonetheless, they have not featured very strongly in existing studies of this type.

There seem to be suitable opportunities for a research-teaching nexus in construction education. Built environment disciplines report teaching via practicals. Examples include use of a construction practice laboratory, at the University of New South Wales, Australia (Davis, 2011). Large-scale engineering competitions, such as the Innovative Learning Week held at the University of Edinburgh (Gillie, Stratford, Bisby \& Furber, 2013), target the challenges of practical real-world engineering, as do construction camps such as Constructionarium, pioneered by Imperial College London in 2003 (discussed below), and the CONCAMP, run by the University of New South Wales in Australia (Fraser, 1990).

The Constructionarium provides a case study of a practical teaching event in the built environment where teaching has been used to support research. The Constructionarium field course module provides a microcosm of a construction site and was used for testing research on a methodology for assessing environmental impacts of construction works. It demonstrates that student project-based learning situations can also help to test the analytical frameworks that academic researcher is developing.

\section{The research: An environmental impact assessment model for construction}

The research problem facing an environmental engineer who is creating a model for predicting the environmental impact of construction works is to validate the model, normally involving many site visits to a long-term commercial construction project. A fast-track solution to this presented itself in the form of the Constructionarium, which is a construction project undertaken by students in just one week. This paper describes the 
research whereby an environmental engineering model was investigated and states how the opportunity of bringing the research together with the teaching has shown the Constructionarium to be a research tool as well as a teaching tool.

It is useful to describe the environmental engineering model investigated for the research, which is part of a PhD undertaken at the Technical University of Catalonia. The aim of the $\mathrm{PhD}$ thesis is to develop a methodology to:

- Evaluate proposed construction works during their design stage: compare different construction options using multi-criteria and select the best choice.

- Monitor the projects during construction: contrast what was planned at the design stage with actual works constructed and request corrections.

Quantifying civil engineering projects in terms of sustainability is a new challenge for the civil engineering industry (Spencer, Hendy \& Petty, 2012). To that end, the four main criteria of this meta-model were defined on the basis of numerous interviews with experts in construction work decision-making, as follows:

- Occupational risks;

- Social impact;

- Environmental impact; and

- Cost.

The part of this research related to occupational risks has already been published (Casanovas, Armengou \& Ramos, 2014). The research performed at Constructionarium focused on the monitoring of the third criterion, environmental impact, during the execution stage of the construction works. Developing the methodology to do this required an initial exhaustive listing of:

- Aspects or criteria to be evaluated during construction. 
- Stages of the construction project life-cycle.

The initial environmental criteria taken into account by the methodology are shown in Figure 1.

Insert Figure 1 about here.

Figure 1. Environmental impact criteria of the general model.

It was known in advance that the Constructionarium's location meant that it would not adversely affect sensitive environments, so this criterion was not included in the study, but the research conducted at the teaching event did test the environmental criteria of the impact model as to resource consumption, pollutants and waste.

Regarding validation of the construction project life-cycle, the stages showed in Figure 2 were initially considered for data collection at Constructionarium, though it was known that it may not be possible to collect the data for all of the stages.

Insert Figure 2 about here.

Figure 2. Life-cycle stages taken into account by the model.

The challenge in developing a tool, such as the impact model, is to balance between elements: collecting valid, good quality data has to balance with the need to collect sufficient data under considerable time-pressure on a commercial construction site. This balance can be achieved by eliminating irrelevant aspects and life-cycle stages and/or using experience of actual construction to identify unfeasible elements of the 
model. Therefore, the methodology needs to be validated and adjusted during real construction work.

\section{Opportunity of Constructionarium as a research site}

The Constructionarium is a 6-day residential field course in hands-on construction for undergraduate students of Civil and Environmental Engineering, held in Norfolk, England at the National Construction College using land dedicated to student-run construction. Four groups of 20 students each, construct scaled-down versions of real civil engineering projects, doing almost all activities of a construction project (setting out, formwork construction, building/erecting, managing time, cost, quality, safety, personnel, training specialists, media relations, contracts and client liaison) and are assessed by senior teachers on the final day regarding team management, cost, quality and time. The concept was created by Expedition Engineering's Chris Wise and Ed McCann and Stef Stefanou of John Doyle Construction.

The teaching team for a Constructionarium joins a university with industry partners. Imperial's academics partnered with consulting (design) engineers, Expedition Engineering, and constructors, John Doyle Construction. The land is rented from the National Construction College and managed by Constructionarium Ltd. The academic perspective combines with industry know-how. The complexity of this organisation can be seen in Figure 3. To find out more on Constructionarium, see Ahearn, Wise, McCann \& Goring (2005) and Ahearn, Popo-Ola, Ciribini \& Girmscheid (2011).

Insert figure 3 about here. 
Figure 3. Participants and projects at the Constructionarium 2012 with Imperial College London.

Evidence demonstrating the value and continued commitment of industry to the Constructionarium as a teaching event includes:

- Take-up by universities: adopted by 19 universities in the United Kingdom

- Industry partnership and funding since 2003, expanded over time.

- Investment of £2.3 million by the Construction Industry Training Board from 2013 for 2 years to further develop the teaching facility (construction site).

- Transfer of the model to nuclear power station construction ('Nuclear Island' project by the Cogent sector skills council, UK).

Constructionarium was used in 2009 for research by Virginia Tech. University into Building Information Modelling but, until the present case, had not been used for environmental research. Inspired by the Virginia Tech experience, we identified the opportunity of testing the methodology for measuring the environmental impact of the construction works at Constructionarium and designed a practical pilot test.

The environmental research benefited Constructionarium because it demonstrated the feasibility of involving students in construction research even whilst they grapple with complex hands-on learning of construction, and it created a means of proposing to other universities the benefits of Constructionarium as a research test site. It made the staff consider complex environmental impact aspects of Constructionarium and was part of environmental consciousness-raising for students. 


\section{Research}

\section{Objectives}

The general objective of the research exercise conducted at Constructionarium was to test the implementation of the methodology for assessing the environmental impact of construction works.

The specific research objectives were:

1. To ascertain what pieces of information are feasible to obtain on real construction sites and in what degree of detail.

2. To judge the difficulty of implementation of the environmental impact assessment tool on a live site.

3. To define the pieces of information required for the final methodology.

\section{Methodology}

In order to evaluate the model at Constructionarium, each criterion in the model was linked to an actual source of data on site. Some criteria had two or more sources from where the data could be obtained so that the information could be compared. Photographs taken during each construction process were also used as a control for the information provided by the other sources. Table 1 links the data to be collected with the source of the data when collected at Constructionarium.

A timetabled talk informed students about the research to be carried out at Constructionarium and to recruit volunteers for data collection responsibilities. Students were instructed to include this role in their team management plan. Volunteers then received more detail on how to collect data and why it mattered. Hence, the students learned about both the content and the process of the research. 
Insert table 1 about here.

Table 1. Source of the data for each environmental impact criterion.

\section{Results and advantages and disadvantages of the exercise}

During the Constructionarium, observations were made of characteristics where the event resembled, and differed from, a real commercial site. Immediately after Constructionarium, these characteristics were analysed to determine whether the Constructionarium exercise was still useful to the research. The following list outlines these characteristics:

1. Duration: All of the construction, from the foundation excavations to topping out the structure, is carried out in a very short period of time, of only six days.

2. Scale: Although scaled down, the projects are big enough to count as construction and to be useful to the research. They are also small enough to be monitorable and controllable as research specimens.

3. Realism: The students construct with real materials, real plant and equipment, real safety risks, real time constrains and a real environmental impact.

4. As can be seen in Figure 3, a considerable number of people work together in different roles on-site, reflecting the complexity of a real construction site.

5. Project documents are much less detailed than on commercial projects, and structures are only built to structural skeleton stage (they are not fitted out nor clad). Even staff only obtain a short project description, the drawings and a construction sequence. Students receive the explanation and the drawings but must work out the construction sequence by themselves. This lack of written data is 
partially compensated by the knowledge of the site staff because they have supervised students building the same projects many times.

6. Data sources: Some sources or ways of collecting data in this study are different from those that would be used in a commercial site. Some data would be easier to obtain in a commercial site, such as energy consumption.

7. Co-operation: A commercial site must prioritise the obligation to the client over the volunteer obligation to a researcher. Constructionarium projects are not commercial projects, which removes the competition between the industry participants, creating greater opportunities for collaboration in the research, feeling free to share their knowledge. This was beneficial to research datagathering but might not reflect the competitive working relationship conditions on a commercial construction site. However, for a fast-track practical test of the environmental impact model, the advantage outweighed a hypothetical disadvantage.

8. The undergraduate students collaborating in the research have little or no experience on site. Not being professionals, they might struggle to collect accurate data whereas commercial construction site workers are more experienced than the students.

9. The activity is residential in a remote location which minimises distractions and enables collaborative discussion amongst students, academics, industry staff and the researcher. This deep immersion into a construction site life can also be a benefit for the researcher.

Table 2 presents the analysis of the advantages and disadvantages of the characteristics listed above and the assigned score assessing its magnitude as high, medium or low. Although there are several disadvantages, there are two important 
advantages that are to collect actual data to input in the model based on an actual piece of construction in an extremely short period of time.

Insert table 2 about here

Table 2. Analysis of the advantages and disadvantages of Constructionarium for performing the environmental impact validation exercise.

The finding was that there is sufficient authenticity in Constructionarium to carry out environmental research and research on other aspects of construction works. Once Constructionarium was accepted as a valid tool for performing this research, the environmental impact model test was continued.

\section{Discussion: Implications of the study}

\section{Ease of data collection}

While doing the research at Constructionarium, some data were easier to collect than others. Following, some examples are presented:

1. The noise made by the power generators was easy to collect and very accurate. Its indicator, equation (1), was defined as the sound power level (LwA) of the machine multiplied by the duration of the noise $(\Delta t)$ :

$$
\text { Noise generation indicator }=\sum L_{W A} \times \Delta t
$$

All the power generators indicated their noise power level and had an automatic timer indicating duration of working. It did not rely on human input and was, in principle, accurate. 
2. The energy consumption of the various items of power-tool equipment used on site was difficult to ascertain. They were used by many different students and staff, and included different types and models of jigsaws, circular saws, concretevibration tool, driller, and compactors with different energy sources (battery, motor-driven with fuel, and electricity). Students distracted by the exigencies of construction of their projects, did not always note the data for the research. This was detected on day 1 by contrasting data collected and noting the verbal comments of the Graduate Teaching Assistants (junior staff). From day 2, the 'plant and equipment sheet' was also completed by the Graduate Teaching Assistants to enhance reliability.

3. There are also examples in which obtaining the data has not been possible. The actual energy consumption, air pollutant emission and $\mathrm{CO}_{2}$ emission produced in the manufacturing and transport of the steel is unknown because the steel supplier has not provided that information.

\section{How the learning event affected the research}

Despite some unrealities of the teaching event, all of the specific research test objectives, as well as the general objective, have been achieved to a satisfactory degree. The teaching event served the research in that:

1. It showed which pieces of information are possible to obtain and in which degree of detail and accuracy, as demonstrated above.

2. Ease of data collection was assessable. Those data not possible to obtain have been identified, as explained in the examples. 
3. After the teaching event test of the model implementation, all of the criteria presented in Figure 1 have been included in the final methodology, and the life cycle stages defined from those shown in Figure 2.

The exercise enabled us to obtain a final version of the environmental assessment model and to approach with confidence the next step which is a validation of the metaimpact model (including occupational risks, social impact and cost) on a commercial construction site.

\section{How the research affected teaching}

As a consequence of the research carried out at Constructionarium, all of the undergraduate students became aware of the research project via a talk in the official briefing. They gained the following insights on the model:

- Construction works can produce the environmental impacts presented in Figure 1.

- Some impacts depend mainly on the construction project itself (resource consumption, pollutants and waste) and others on the location of the project (impact on sensitive environments).

- Apart from the construction work phase, environmental impacts are also produced in other stages (Figure 2).

By using the Constructionarium teaching tool as a research tool, the volunteer students had the research process explained and they participated; they engaged with the intellectual content and the applied process of research. The use of a teaching field-trip as a research-data gathering event has the added advantage of acting as a low-level introduction to professional, industrial or university research. This demonstrates that 
teaching which supports research can yield research which supports teaching, as Figure 4 illustrates. The two volunteers in each team were also assessed in terms of interest and collaboration in the research and the accuracy of the collected data.

However, the Constructionarium teaching tool supported the research much more intensely than the research supported the teaching, as can be seen from the arrows in Figure 4. The key is that there is closed loop in the relationship between teaching and research.

Figure 4. Diagram showing that a few interventions from a sole researcher enabled the teaching tool to unlock a significant level of input to the research, justifying the 'research-teaching nexus’ claim.

\section{Conclusions}

\section{Summary of what has been deduced in practice}

The paper presents a case study in which a teaching tool, the Constructionarium projectbased teaching event, has been used as a research tool. The limitations of a student construction site compared to a commercial construction site have been identified as:

- Lack of detail in the project briefs.

- Some differences in sources of data.

- Less competitive working relationships.

- The student engineers collecting the data lack experience.

The advantages of the Constructionarium teaching event for research are identified as:

- Speed of data acquisition.

- Minimal cost. 
- A small enough scale to enable a sole researcher to gain an overview of wholesite operation from start to end of a project.

- Co-operation from and access to all levels of workers and to expert supervisors who hold research in high esteem.

It is a microcosm of real-life engineering with real materials, real plant and equipmentand thus a real environmental impact. Therefore, Constructionarium teaching event was found to be realistic enough to perform valid environmental research about construction site work practices. The case study showed the Constructionarium to be a research tool as well as a teaching tool. This highlights the unexploited research potential of the Constructionarium teaching tool specifically and of field-trip teaching events generally.

\section{Developing further the two-way link between research and teaching}

The study case clearly illustrates how teaching can support research. At the same time and as a consequence, the research has also supported teaching in three ways:

1. The general content of the research has become known to all students.

2. The detailed content of the research has become known to the volunteer's subset of students.

3. The process of the research has been taught to staff as well as volunteer students.

\section{Guidance to other researchers in testing their models with students}

Many universities run Constructionarium modules, widening the opportunities for any researcher interested in fast-track acquisition of data regarding the real aspects of construction (materials, plant and equipment, cost, construction works and methods, 
environmental impact, occupational health and safety, building information modelling, human resource management, technology, etc.). The time-compressed, complex teaching event provides an advantage to researchers on a limited budget with limited time. Future studies may find different advantages and disadvantages given a different nature of their research but the benefits of a microcosm seem likely to persist.

Teachers proposing complex teaching events may benefit from highlighting the research opportunity for fast-tracked data acquisition and the resource advantage of student data-gatherers. Whilst the researcher clearly benefits from utilising complex teaching events as a research tool, the researcher can also demonstrate to funding bodies that their research is directly giving students exposure to research.

This experience encourages the use of other practical teaching events as a research tool, making the research-teaching nexus into a two-way link.

\section{Acknowledgements}

Authors would like to thank the technicians, the graduate teaching assistants and the students who volunteered from Imperial College London; the John Doyle Construction team and the Constructionarium team for their collaboration on the research held at the well-developed facilities at the National Construction College.

\section{Funding}

This work was supported by the Spanish Ministry of Economy and Competitiveness under the [grant number BIA2006-15471-C02-01] project and the Spanish Civil Engineer Association. 


\section{Notes on contributors}

Maria del Mar Casanovas-Rubio, a PhD student at the Universitat Politècnica de Catalunya, has taught Environmental Management and Sustainable construction at postgraduate level and her research centres on assessing the environmental impact, social impact and occupational risks of construction work.

Alison Ahearn is a principal teaching fellow in the Department of Civil and Environmental Engineering at Imperial College London and a co-founder of the Constructionarium mode of practical learning in construction. She coordinates the business management option modules on the Civil Engineering taught postgraduate courses, for which she examines the construction law and project management modules.

Gonzalo Ramos is a full professor at Universitat Politècnica de Catalunya where he teaches Construction procedures and Bridges for undergraduate students and Construction Industry practice for postgraduate students. He has published widely on these areas.

Sunday Popo-Ola is a research and teaching fellow at Imperial College London, specialising in industry-focused lab-based research on steel and concrete structures, as well as coordinating undergraduate classes on Creative Design and co-teaching and developing Constructionarium.

\section{References}

Ahearn, A., Wise, C., McCann, E., \& Goring, P. (2005) Constructionarium: Building to Learn. Transactions, 2, 6-16. 
Ahearn, A., Popo-Ola, S., Ciribini, A., \& Girmscheid, G. (2011, November) A cultural divide? Different modes of teaching construction management. First EUCEET Association Conference: New Trends and Challenges in Civil Engineering Education. Patras, Greece.

Barnett, R. (2005). Reshaping the university: New relationships between research, scholarship and teaching. Maidenhead: Open University Press.

Brew, A. (2001). The nature of research: Inquiry in academic contexts. London: Routledge Falmer.

Brew, A. (2006). Research and teaching: Beyond the divide. London: Palgrave Macmillan.

Casanovas, M., Armengou, J., \& Ramos, G. (2014). Occupational risk index for asessment of risk in construction work by activity. Journal of Constuction Engineering and $\quad$ Management, 140, http://ascelibrary.org/doi/abs/10.1061/\%28ASCE\%29CO.1943-7862.0000785

Davis, S. R. (2011, December). Creation of a construction practice laboratory. Australasian Association for Engineering Education Conference 2011: Developing engineers for social justice: Community involvement, ethics \& sustainability, Fremantle, Western Australia.

Elsen, M., Visser-Wijnveen, G. J., van der Rijst, R. M., \& van Driel, J. H. (2009). How to strengthen the connection between research and teaching in undergraduate university education. Higher Education Quarterly, 63, 64-85.

Fraser, D.J. (1990, December). Darlington point bridge reconstruction. Fifth National Conference on Engineering Heritage 1-8. Perth, WA.

Gillie, M., Stratford, T., Bisby, L., \& Furber, A. (2013). Trebuchets and bridges: Reconnecting sructural education with the real world. Journal of Professional 
Issues in Engineering Education and Practice, 140, 1-3. 10.1061/(ASCE)EI.1943-5541.0000185.

Griffiths, R. (2004). Knowledge production and the research-teaching nexus: the case of the built environment disciplines. Studies in Higher Education, 29, 709-726.

Healey, M. (2005a). Linking research and teaching: Disciplinary spaces. In R. Barnett (Ed.), Reshaping the university: New relationships between research, scholarship and teaching (pp. 30-42). Maidenhead: Open University Press.

Healey, M.(2005b). Linking research and teaching to benefit student learning. Journal of Geography in Higher Education, 29, 183-201.

Healey, M., Jordan, F., Pell, B., \&Short, C. (2010). The research-teaching nexus: a case study for students' awareness, experiences and perceptions of research. Innovations in Education and Teaching International, 47, 235-246.

Jenkins, A., Breen, R., Lindsay, R., \&Brew, A. (2003). Re-shaping higher education: Linking teaching and research. London: Routledge/SEDA.

Jenkins, A., \& Healey, M. (2005). Institutional strategies to link teaching and research. York: The Higher Education Academy.

Jenkins, A., Healey, M., \& Zetter, R. (2007). Linking research and teaching in disciplines and departments. York: Higher Education Academy.

Kreber, C. (Ed.). (2006). Exploring research-based teaching. New directions in teaching and learning. San Francisco: Jossey-Bass/Wiley.

Prince, M. J., Felder, R. M., \& Brent, R. (2007). Does faculty research improve undergraduate teaching? An analysis of existing and potential synergies. Journal of Engineering Education, 96, 283-294.

Spencer, P. C., Hendy, C. R., \& Petty, R. (2012) Quantification of sustainability principles in bridge projects. Proceedings of the ICE - Bridge Engineering, 165, 81-89. 
Table 1. Source of the data for each environmental impact criterion.

\begin{tabular}{|c|c|c|c|}
\hline \multicolumn{3}{|c|}{ ENVIRONMENTAL IMPACT } & \multirow[b]{2}{*}{ SOURCE OF THE DATA } \\
\hline Criteria & Subcriteria & Life-cycle stages & \\
\hline \multirow{6}{*}{$\begin{array}{l}\text { Resource } \\
\text { consumption }\end{array}$} & $\begin{array}{c}\text { Materials } \\
\text { (concrete, } \\
\text { steel, timber) }\end{array}$ & Construction work & $\begin{array}{l}\text { 'Material sheet' to be filled with the material consumption } \\
\text { by the students at Constructionarium and contractor } \\
\text { purchase order documents. }{ }^{1}\end{array}$ \\
\hline & \multirow[b]{5}{*}{ Energy } & Raw material extraction & \multirow{4}{*}{$\begin{array}{l}\text { Data sheets on the material suppliers' websites and } \\
\text { information provided by the material suppliers by e-mail. } \\
\text { (a) }\end{array}$} \\
\hline & & Transport of raw materials & \\
\hline & & $\begin{array}{l}\text { Manufacturing of } \\
\text { construction materials }\end{array}$ & \\
\hline & & $\begin{array}{l}\text { Transport of construction } \\
\text { materials }\end{array}$ & \\
\hline & & Construction work & $\begin{array}{l}\text { 'Plant and equipment sheet' to be filled with the duration } \\
\text { of the use of the machinery and equipment by the students } \\
\text { and Graduate Teaching Assistants at Constructionarium, } \\
\text { fuel consumption provided by the driver of the plant and } \\
\text { reading of the timer of the power generator by the } \\
\text { researcher plus the medium fuel consumption per unit of } \\
\text { time provided by the store man. }{ }^{1} \text { (b) }\end{array}$ \\
\hline \multirow{13}{*}{$\begin{array}{l}\text { Pollutant and } \\
\text { waste }\end{array}$} & \multirow{5}{*}{ Air pollution } & Raw material extraction & \multirow{4}{*}{ The same as in (a) } \\
\hline & & Transport of raw materials & \\
\hline & & $\begin{array}{l}\text { Manufacturing of } \\
\text { construction materials }\end{array}$ & \\
\hline & & $\begin{array}{l}\text { Transport of construction } \\
\text { materials }\end{array}$ & \\
\hline & & Construction work & $\begin{array}{l}\text { The same as in (b) plus research of the air pollution } \\
\text { generation per unit of fuel consumption and type of fuel. }{ }^{1}\end{array}$ \\
\hline & \multirow{5}{*}{$\begin{array}{l}\text { Emission of } \\
\text { greenhouse } \\
\text { gases }\end{array}$} & Raw material extraction & \multirow{4}{*}{ The same as in (a) } \\
\hline & & Transport of raw materials & \\
\hline & & $\begin{array}{l}\text { Manufacturing of } \\
\text { construction materials }\end{array}$ & \\
\hline & & $\begin{array}{l}\text { Transport of construction } \\
\text { materials }\end{array}$ & \\
\hline & & Construction work & $\begin{array}{l}\text { The same as in (b) plus research of the } \mathrm{CO}_{2} \text { generation per } \\
\text { unit of fuel consumption and type of plant and equipment. }\end{array}$ \\
\hline & $\begin{array}{l}\text { Noise } \\
\text { generation }\end{array}$ & Construction work & $\begin{array}{l}\text { 'Plant and equipment sheet' to be filled with the duration } \\
\text { of the use of the machinery and equipment by the students } \\
\text { and Graduate Teaching Assistants at Constructionarium } \\
\text { and Noise Power Level (LwA) of the plant and equipment } \\
\text { indicated in the plant and equipment itself or in their } \\
\text { operator manual. }\end{array}$ \\
\hline & $\begin{array}{l}\text { Waste } \\
\text { generation }\end{array}$ & Construction work & $\begin{array}{l}\text { 'Waste sheet' to be filled by the students at } \\
\text { Constructionarium and recount of the number of skips of } \\
\text { waste generated. }{ }^{1}\end{array}$ \\
\hline & $\begin{array}{l}\text { Toxic, } \\
\text { pollutant or } \\
\text { dangerous } \\
\text { waste } \\
\text { generation. }\end{array}$ & Construction work & Reported by the contractor team. \\
\hline
\end{tabular}

${ }^{1}$ Each project team had one or two students responsible for collecting the environmental data by filling in three sheets each day. As each team had a cost-monitoring student, we decided that this student would collect the environmental data because s/he had to collect 
similar data for the cost monitoring. The second student helping in the environmental research was a volunteer among the other students in the team. 
Table 2. Analysis of the advantages and disadvantages of Constructionarium for performing the environmental impact validation exercise.

\begin{tabular}{|l|l|c|c|}
\hline Characteristics of Constructionarium construction & \multicolumn{2}{|c|}{ Assessment } \\
\cline { 2 - 3 } \\
projects & Advantage & Disadvantage \\
\hline 1 & 6-day duration. & High & - \\
\hline 2 & Scaled-down projects. & Low & - \\
\hline 3 & Real construction, real environmental impact. & High & - \\
\hline 4 & Complexity of a real construction site. & - & - \\
\hline 5 & Lack of detail in the project documents. & - & Medium \\
\hline 6 & Different data sources from a commercial site. & Medium \\
\hline 7 & $\begin{array}{l}\text { Good access to the staff without commercial } \\
\text { pressures. }\end{array}$ & & Low \\
\hline 8 & $\begin{array}{l}\text { Lack of experience on site for the students } \\
\text { collaborating on the research. }\end{array}$ & - & - \\
\hline 9 & Residential activity with deep immersion. & Low & - \\
\hline $\begin{array}{l}\text { Total score of the advantages and total score of the } \\
\text { disadvantages }\end{array}$ & $\begin{array}{l}\text { +2 High } \\
+2 \text { Medium } \\
+2 \text { Low }\end{array}$ & \begin{tabular}{c} 
2 Low \\
\hline
\end{tabular} \\
\hline
\end{tabular}




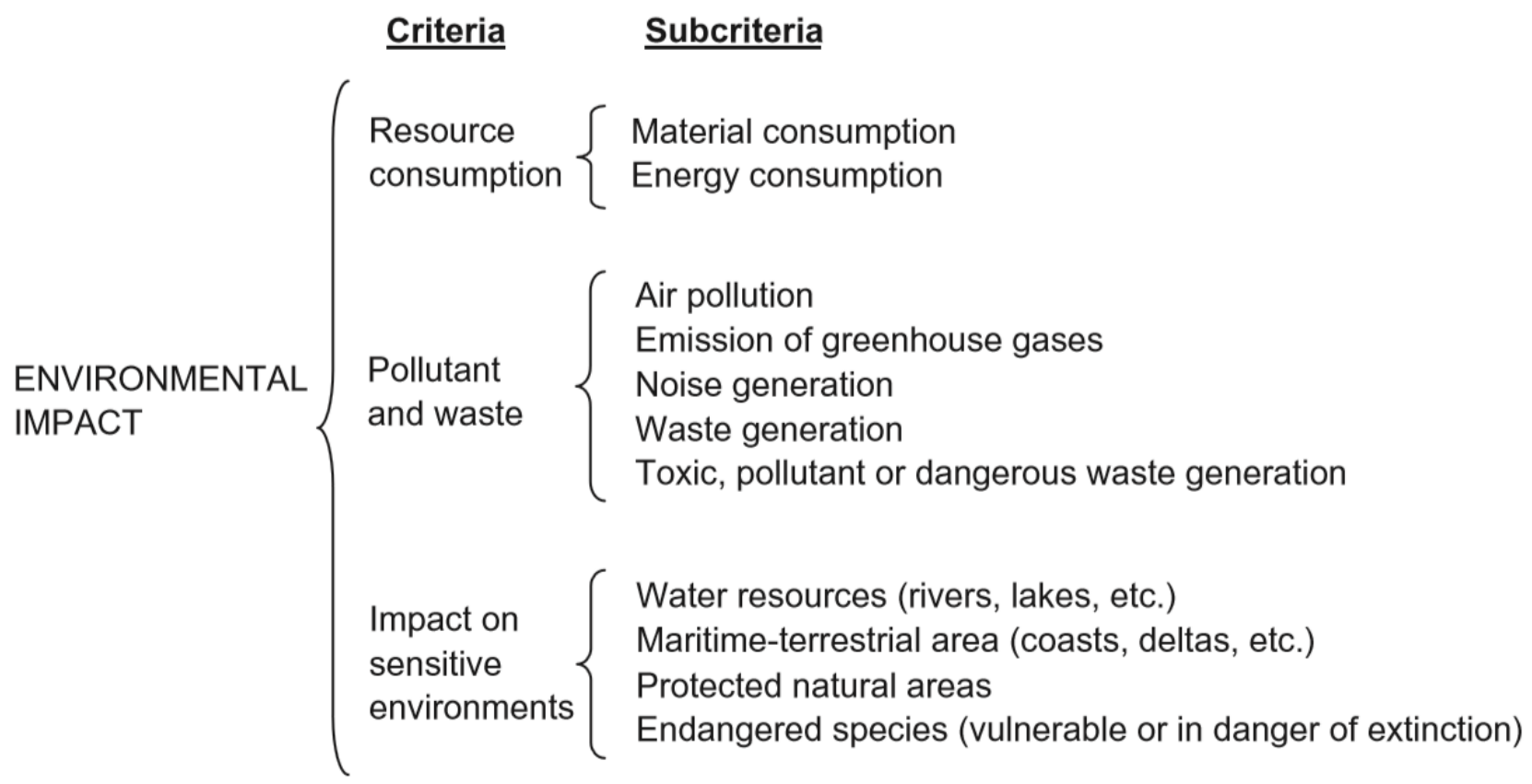

Figure 1. Environmental impact criteria of the general model. 
Transport of

Transport of

Raw material

extraction raw materials

Manufacturing of construction materials
Construction work

Figure 2. Life cycle stages taken into account by the model. 


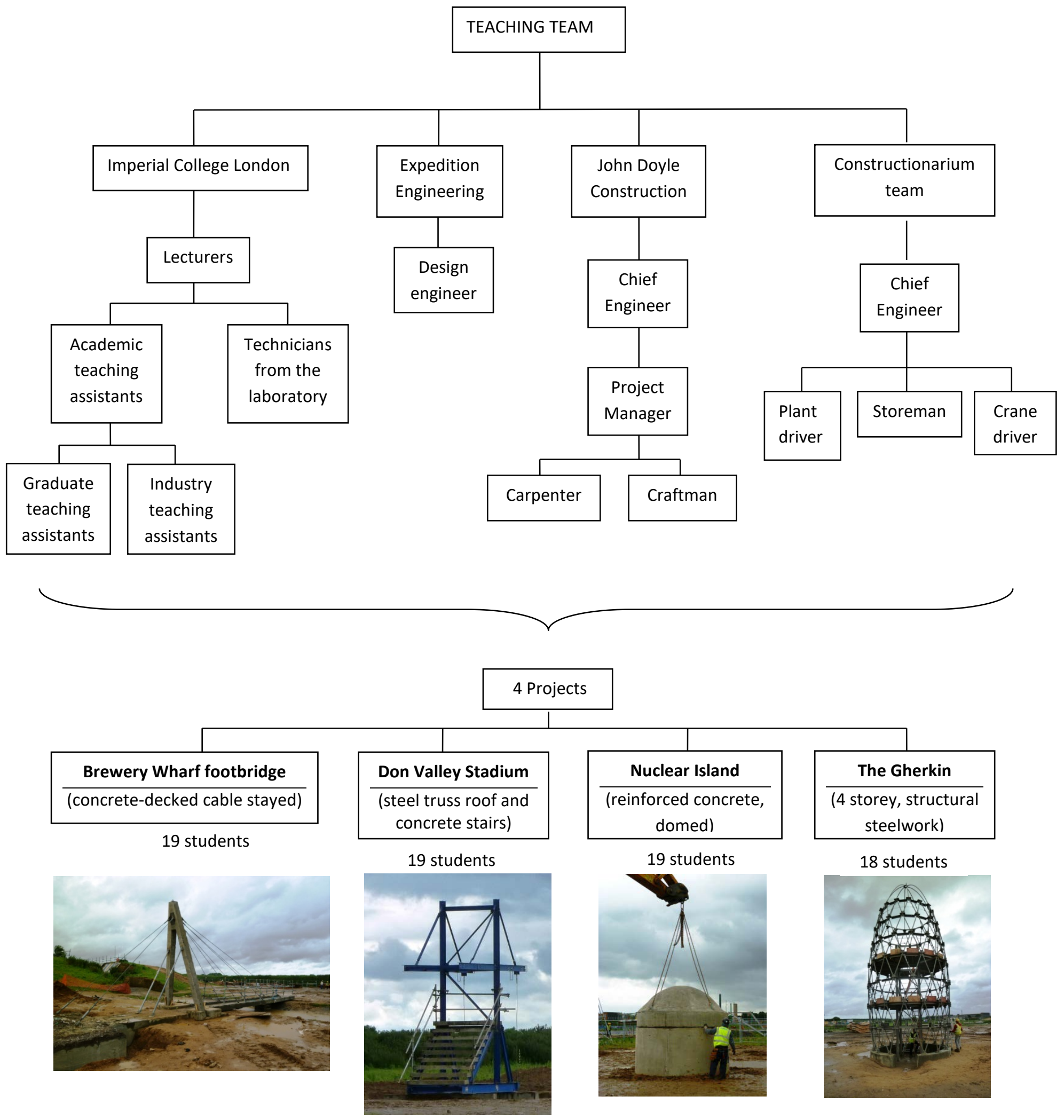

Figure 3. Participants and projects at the Constructionarium 2012 with Imperial College London. 
Research supported by volunteer students, academics and industry staff

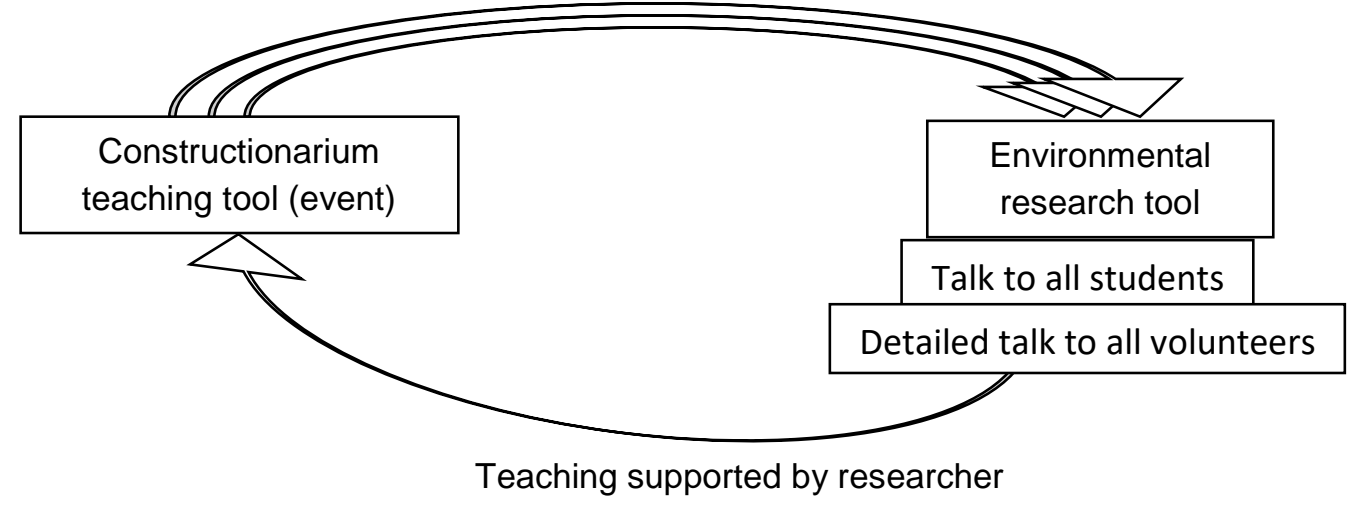

Figure 4. Diagram showing that a few interventions from a sole researcher enable the teaching tool to unlock a significant level of input to the research, justifying the ‘research-teaching nexus’ claim. 